\title{
Analysis of Energy and Exergy of a Two-Circuit Solar Installation with Thermosiphon Circulation
}

\author{
${ }^{1}$ KUNELBAYEV M., ${ }^{2}$ OMAROV R., ${ }^{3}$ KURT E., ${ }^{4}$ OMAR D. \\ ${ }^{1}$ The Institute of Information and Computational Technologies CS MES RK, Almaty, \\ KAZAKHSTAN \\ ${ }^{2,4}$ Kazakh Scientific Research Institute of Mechanization and Electrification of Agriculture, \\ Almaty, KAZAKHSTAN \\ ${ }^{3}$ Gazi Üniversitesi, Ankara, TURKEY
}

\begin{abstract}
In this paper, a new system is proposed to improve the thermodynamic and economic indicators of solar room heating. The heat pump is integrated with a conventional solar heating system, in which the temperature of the collected heat is reduced by $20^{\circ} \mathrm{C}$ to $30^{\circ} \mathrm{C}$ to increase the efficiency of solar energy collection. The low-temperature heat collected by the solar collector is increased using a heat pump to generate high-temperature heat for indoor heating in winter and low-pressure process steam for industrial use in other seasons. The results show that the efficiency of the solar collector has increased by $30.50 \%$, its annual effective operating time has reached 2000 hours, which is about four times more than that of a conventional solar heating system. In addition, the parameters of the solar collector area, the volume of the storage tank and the power of the heat pump have been optimized. This work provides a new way to use solar energy more efficiently and economically. Energy analysis shows that with the new flat solar collectors, the average annual values were $2.5 \mathrm{~kW}$, and also high, the COP system in November was $4 \%$.
\end{abstract}

Key-Words:- Flat solar collector, thermal model, thermal efficiency, analysis of energy and exergy, a twocircuit solar installation with thermosiphon circulation

Received: April 27, 2021. Revised: October 10, 2021. Accepted: November 2, 2021. Published: November 29, 2021.

\section{Introduction}

Due to the severity of problems with lack of energy and environmental pollution, to which they are exposed in winter, heating of premises is usually provided by natural gas or electricity [2]. In [3,4], numerous cogeneration and trigeneration systems were developed for more efficient use of natural gas and reduction of its consumption. For indoor heating, it is considered an important way to ensure the safety of gas supply and reduce $\mathrm{CO} 2$ emissions to replace natural gas using solar energy [6]. To compensate for the discrepancy between the demand for heat and heat generation, solar heating systems are usually integrated with energy storage equipment [7]. The equipment for short-term energy storage used in solar heating systems are hot water tanks [8], and phase transitions were also used [9]. In the work [10], the technical and economic indicators of the solar-based indoor heating system were evaluated and it was shown that solar energy can provide a significant share of the heating needs of premises in high latitudes, In the article [11] various district heating systems based on solar energy were compared. In [12], the technical and economic characteristics of the solar central heating system in the UK were investigated. The article [13] studied the potential of central heating solar power plants in the European Union from both economic and environmental points of view. In [14], the expediency of using solar district heating in China was discussed and that the integration of solar district heating with a geothermal heat pump was a reliable solution. In winter, the efficiency of the solar collector tends to decrease due to the low ambient temperature and increased heat loss [15]. The combination of solar heating with a heat pump increases not only the performance of the heat pump, but also the efficiency of the solar collector [15]. The new system performs these functions; it recycles heat, organizes their movement and accumulation, and smooths out the uneven SE. The main components of the 
system are: Solar Power Plant (SPP), milk cooler, climate unit, Heat Pump (HP), the battery heat, automatic control system, and device heating and hot water. The main goal, i.e. lower cost of the energy produced and the elimination of the uneven SE, compared to the known SPP, is achieved through the flow of energy from the sources mentioned above [16].This article is devoted to experimental studies of a heat pump with microprocessor control on an animal farm. During the experiment, three versions of the heat pump were used. The compressor is better cooled when it is closer to the evaporator than when it is located centrally, this indicates a higher cooling capacity, which can be observed according to the heat energy meter shown in Fig.

8. The milk temperature during the experiment is reduced from 35 to $100 \mathrm{C}$. The best temperature mode of the condenser is provided when the compressor is located near the evaporator. It is lower by 7-80C than in the other 2 variants. The results show that the location of the compressor affects the performance of the VT. The values of the energy conversion coefficient in two variants are from 2.5 to 4.5 units. In the third variant it is 4.5 , which is $10 \%$ higher than in the 2 nd and $15 \%$ than in the 1 st variant [17].

\section{Method of Research}

The experimental setup was manufactured and tested in the laboratory of the Institute of Information and Computing Technologies of the Ministry of Education and Science of the Republic of Kazakhstan

Figure 2 shows a model of a flat solar collector. The essence and novelty of the proposed one is that, unlike the well-known design principle, the collector contains a transparent double-glazed window 2 with double glass and with reduced pressure, as well as a perimeter frame 1 . The bottom of the wooden frame 7 is made of $8 \mathrm{~mm}$ thickness plywood. and heat-insulating film 5 with foil is glued to it. In the gap, formed between the double-glazed window and the bottom of the frame, a flexible thin-walled stainless corrugated tube of $4-16 \mathrm{~mm}$ is laid in the coil form. The edges of the tube are attached to the inlet and outlet protruding pipes 6 .

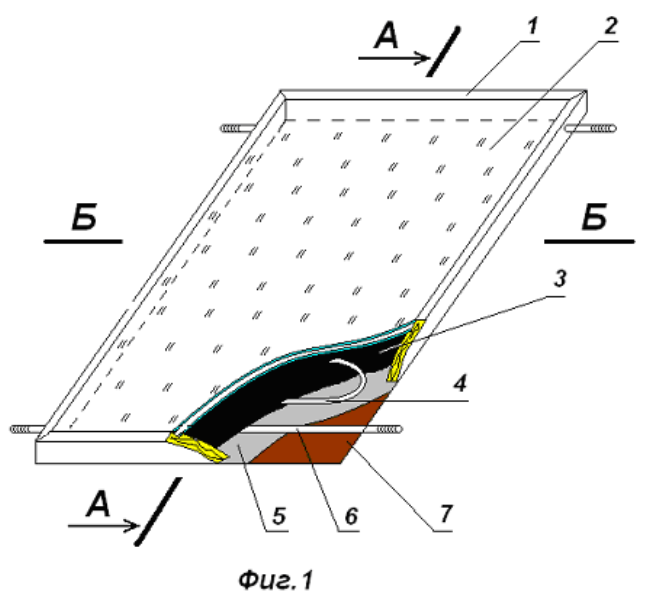

Fig.1 Principal diagram of flat solar collector

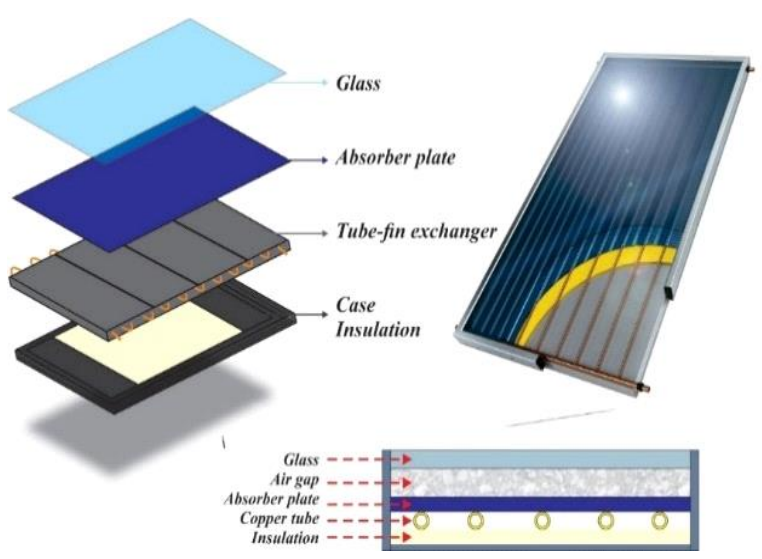

Fig.2 Principal diagram of flat solar collector in parts

As shown in Figure 2, the solar energy passes through the glass and hits the absorber plate, which heats up, converting solar energy into thermal energy. Heat is transferred to the working fluid, which passes through tubes, attached to the absorber plate.

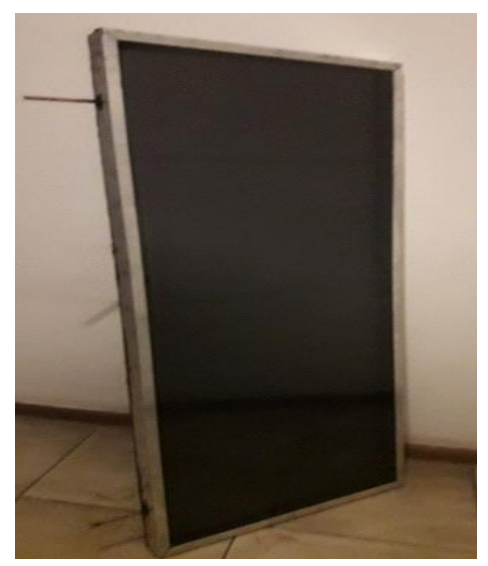




\section{Fig.3 Flat solar collector mockup}

Figure 3 shows a full-scale model of a flat solar collector. The solar collector is the main heat generating unit of the solar installation. To achieve this goal, we have developed a fundamentally new flat solar collector, on the basis of which various types of solar systems will be created, both according to sizes and design, applied to water heating and premises heating.

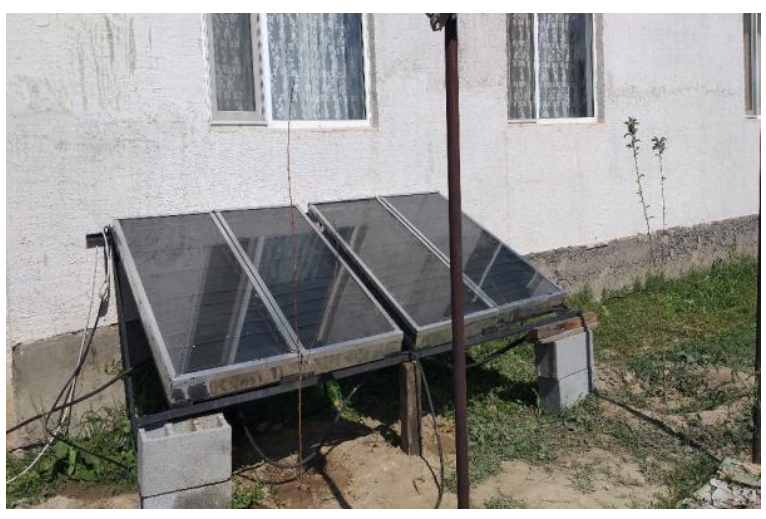

Fig.4 Test bench

The novelty of this study is the development of a flat solar collector, which is a heat-insulating transparent double-glazed window with reduced pressure, and the coolant is made of thin-walled corrugated stainless pipe. The heat received from the solar flux heats the liquid in the coils, which is removed from the collector, there is a constant thermal circulation, which increases the efficiency of heat transfer, eliminating additional intermediate walls between the panel and thermal insulation. There is also a stagnant air gap, which reaches higher temperatures than the ambient temperature, due to the heat lost from the upper glass. The higher the temperature difference between the stagnant air gap and the environment, the higher the internal wind speed. In the case of constant ambient temperatures, the temperature difference between the stagnant air gap and the environment increases with increasing operating temperature, which leads to an increase in the overall loss coefficient. Whereas, if there is a spontaneous gradual change in ambient temperature, the speed of the internal wind decreases, and vice versa. The performance provided by the developed flat solar collector is carried out by developing an experimental model.

Laboratory stands were made for experimental studies. The main element of the scheme under study is a heat pump. Figure 3 shows a diagram of the new technical solution of the heat pump in the section. The proposed device allows you to use the heat generated by the compressor during operation and simultaneously cool it.

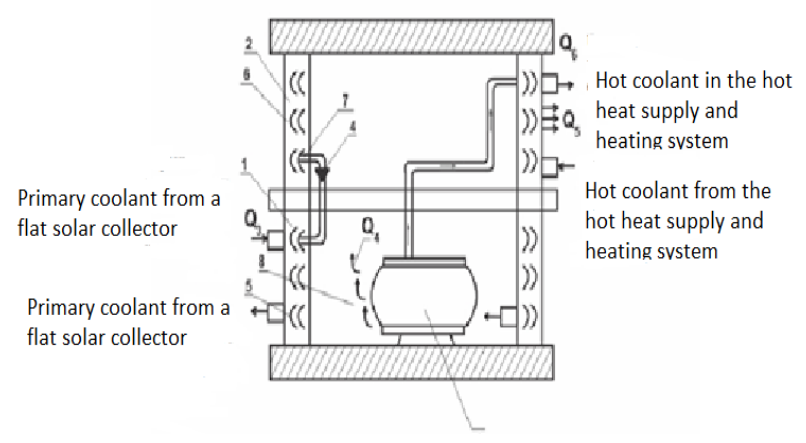

Fig. 5 Diagram of the new technical solution of the TP in the context.

In this case, 1 is a heat exchanger; 2 is a condenser; 3 is a compressor; 4 is a throttle valve; 5 and 6 are the coolant pipes of the evaporator and condenser; 7 is a hole for inserting tubes into the condenser housing; 8 is an air flow separator with a mesh shell.

The heat exchangers of the evaporator 1 and the condenser 2 are made in the form of annular tanks formed by inner and outer cylindrical shells with radii R1 and R2, and are installed coaxially above each other in the lower part of the evaporator. above the condenser, forming an internal cylindrical air cavity. A compressor 3 is installed in the cavity of the evaporator heat exchanger. To ensure optimal heat transfer from the compressor to the evaporator, a mesh cylindrical separator shell 8 is placed in the gap between them. The refrigerants of the $1 \mathrm{st}$ and 2nd circuits circulate inside the annular tanks, removing heat from the pipes 5 and 6 . Thus, the compressor is practically located inside the "cold bath", the walls of which are cooled by the coolant of the pipes 5. As a result, the heat generated by the compressor is absorbed by the TP evaporator, increasing its performance, and 
the compressor is simultaneously cooled without using a fan.

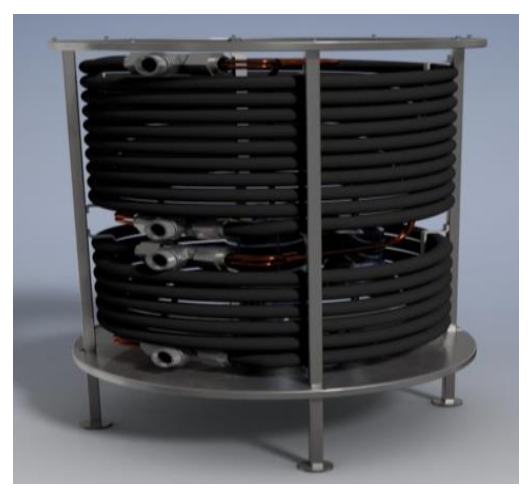

a)

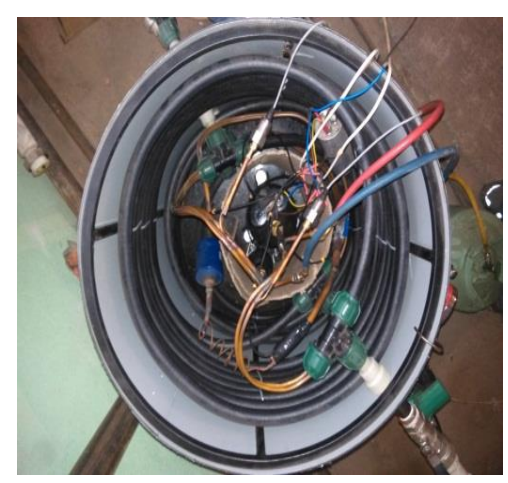

b)

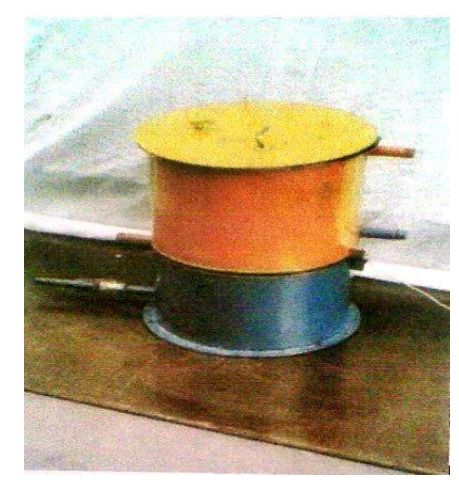

c)

Fig.6 Heat pump

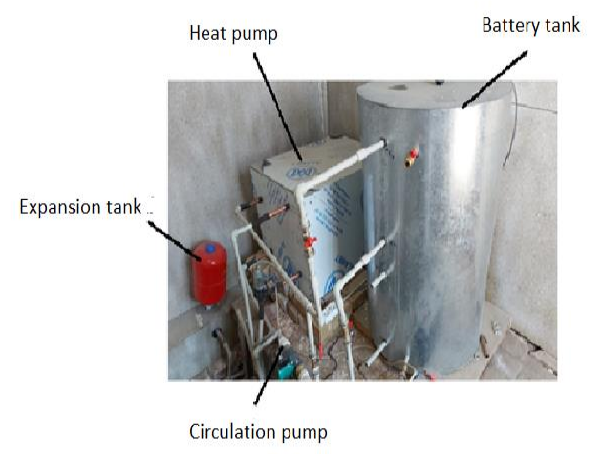

Fig.7 Industrial design and general view of an automated 2-contour solar installation

The novelty of this research is the development of a two-circuit solar system with thermosiphon circulation, which has a flat solar collector, which is a heat-insulating transparent doubleglazed window with reduced pressure, and the coolant is made of thin-walled corrugated stainless pipe. The heat received from the solar flux heats the liquid in the coils, which is removed from the collector, and in its place comes cold liquid from the siphon and there is a constant thermal circulation, which increases the efficiency of heat transfer, eliminating additional intermediate walls between the panel and thermal insulation. There is also a heat pump, where the condenser and evaporator are made in the form of a spiral heat exchanger, the heat exchanger pipelines are located one above the other, which increases the area, as well as the intensity of heat exchange [15].

\section{Thermodynamic model}

The useful energy of the collector can be calculated using one of the following two equations:

$$
\begin{aligned}
& Q_{U}=\dot{m} C_{p}\left(T_{\text {out }}-T_{\text {in }}\right) \\
& \mathrm{Q}_{U}=A_{c} F_{R}\left[I_{T}(\tau \alpha)-\mathrm{U}_{L}\left(T_{\text {in }}-T_{\text {amb }}\right)\right]
\end{aligned}
$$

where $\mathrm{m}$ is the mass flow rate, $\mathrm{CP}$ is the specific heat capacity of the liquid, Tout is the temperature at the outlet of the working fluid, Tin is the temperature at the inlet of the working fluid, AC is the collector area, this is the total radiation, $\tau$ is the transmittance of the glass, $\alpha$ is the absorption capacity of the collector and Tam is the ambient temperature.

The heat transfer coefficient $\left(F_{R}\right)$ can be calculated using the following equation:

$$
F_{R}=\frac{m C_{p}\left(T_{\text {out }}-T_{\text {in }}\right)}{A_{c}\left[I_{T}(\tau \alpha)-U_{L}\left(T_{\text {in }}-T_{\text {amb }}\right)\right]}
$$

The total radiation received by the collector can be calculated using the following equation: 
$Q_{T}=A_{c} I_{T}$

The instantaneous efficiency of the collector can be calculated as follows:

$\eta=\frac{Q_{\text {usegul }}}{Q_{T}}=\frac{m C_{p}\left(T_{\text {out }}-T_{\text {in }}\right)}{A_{c} I_{T}}=F_{R}\left[(\tau \alpha)-U_{L} \frac{\left(T_{\text {in }}-T_{\text {anb }}\right)}{I T}\right]$

The characteristics of heat pump systems are evaluated from the point of view of energy and exergetic analysis using the first and second laws of thermodynamics, respectively. This section presents thermodynamic equations used to predict the thermodynamic characteristics of heat pump systems.

The general equation of mass balance in a heat pump is expressed as follows:

$\sum \dot{m}_{\text {in }}=\sum \dot{m}_{\text {out }}$

The energy balance of the heat pump system is determined by:

$Q_{\text {cond }}=Q_{\text {eva }}+W_{\text {comp }}$

The compressor power consumption is determined by the following equation:

$$
W_{\text {comp }}=\frac{m_{r}\left(h_{2}-h_{1}\right)}{\eta_{\text {mech }} * \eta_{\text {ele }}}
$$

The mass flow rate of the refrigerant is determined using the following equation: $m_{r}=\frac{V_{d i s} \eta_{v o l} N}{60 v_{1}}$

The heat capacity of the heat pump condenser is determined by:

$$
Q_{\text {cond }}=\dot{m}_{r} c_{p, f}\left(T_{c o}-T_{c i}\right)
$$

The amount of solar radiation absorbed during the evaporation of the refrigerant, as well as due to the effect of overheating, is determined by: $\mathrm{Q}_{\text {solar }}=A_{c}\left(\mathrm{G} \alpha-\mathrm{U}_{t}\left(T_{0}-T_{p l}\right)\right)$

The amount of heat absorbed by the refrigerant during its phase transition from liquid to steam is determined by the following equation:

$$
\mathrm{Q}_{\text {eva }}=\dot{m}_{r}\left(h_{1}-h_{4}\right)
$$

The efficiency of the heat pump system is determined by the following equation:

$$
C O P=\frac{Q_{\text {cond }}}{W_{\text {comp }}}
$$

\section{Exergetic efficiency}

When studying the exergetic efficiency of the system, certain assumptions must be made, for example, the system must operate in a stable state and with a constant flow, the input effect is the only loss factor taken into account, and heat transfer to the system and transfer of work from the system are positive. The effects of kinetic and potential energy deviations are ignored.

$$
\dot{E} x_{\text {in }}+\dot{E} x_{\text {out }}+\dot{E} x_{s t}+\dot{E} x_{\text {leak }}+\dot{E} x_{\text {dest }}=0
$$

where $\mathrm{Ex}_{\mathrm{in}}$ is the exergy coefficient at the entrance to the system, Ex $x_{\text {out }}$ is the exergy coefficient at the exit from the system, Ex $x_{\text {st }}$ is the stored exergy coefficient for the system, $\mathrm{Ex}_{\text {leak }}$ is the leakage exergy coefficient for the system, and $\mathrm{Ex}_{\text {deat }}$ is the exergy destruction coefficient. The rate of exergy destruction $\left(\mathrm{Ex}_{\text {dest }}\right)$ can be determined as follows

$$
\dot{E} x_{\text {dest }}=T_{\alpha} \dot{S}_{g e n}
$$

The exergy flow rate at the inlet (Xin) consists of a liquid flow component (Esin,f) and a component of absorbed solar energy (Exin,s):

$\dot{E} x_{i n, f}=\dot{m} C_{p, N F}\left(T_{i}-T_{\alpha}-T_{\alpha} \ln \left(T_{i} / T_{\alpha}\right)\right)+\frac{m \dot{\Delta} P_{i n}}{\rho}$

where $T_{i}$ is the surface temperature of the sun, equal to $5770 \mathrm{~K}$, and $\mathrm{P}_{\text {in }}$ is the liquid pressure at the inlet.

The exergy flow at the outlet $\left(\mathrm{Ex}_{\mathrm{out}}\right)$ has a liquid flow component and is calculated as the exergy flow at the liquid inlet: $E x_{i n, s}=I_{T} A_{c}\left(1-\frac{T_{\alpha}}{T_{s}}\right)$ 
where Ts is the surface temperature of the sun, equal to $5770 \mathrm{~K}$, and Pin is the liquid pressure at the inlet.

The exergy flow at the outlet $\left(\mathrm{Ex}_{\text {out }}\right)$ has a liquid flow component and is calculated as the exergy flow at the liquid inlet:

$$
\dot{E} x_{\text {out }, f}=\dot{m} C_{p, N F}\left(T_{0}-T_{\alpha}-T_{\alpha} \ln \left(T_{0} / T_{\alpha}\right)\right)+\frac{m \Delta P_{o u t}}{\rho}
$$

where Pout is the fluid pressure at the outlet.

The total entropy generation rate of a nonisothermal solar flat collector, is determined as follows:

$$
\dot{S}_{g e n}=\dot{m} C_{p, N F}\left(\ln \left(T_{0} / T_{i}\right)\right)-\frac{q_{a b s}}{T_{s}}+\frac{q_{\text {loss }}}{T_{\alpha}}
$$

where $\mathrm{q}_{\mathrm{abc}}$ is the energy absorbed by the collector-absorber surface, which can be calculated by the equation $\mathrm{q}_{\mathrm{abc}}=\alpha \tau\left(\mathrm{ITA}_{\mathrm{c}}\right)$, and qloss is the total heat lost to the environment, which can be calculated by the following equation:

$q_{\text {loss }}=q_{a b s}-\dot{m} C_{p, N F}\left(T_{0}-T_{i}\right)$

The exergetic efficiency can be calculated as follows:

$$
\eta_{e x}=\frac{E x_{o u t, f}-E \dot{x}_{i n, f}}{E \dot{x}_{i n, s}}
$$

Using equations (9), (10) and (11), the equation can be rewritten as follows:

$$
\eta_{e x}=\frac{m\left[C_{p, N F}\left(T_{0}-T_{i}-T_{\alpha} \ln \left(T_{0} / T_{i}\right)\right)-\Delta P / \rho\right]}{q_{a b s}\left(1-T_{o} / T_{s}\right)}
$$

Using equations (12)-(14), the exergetic efficiency can also be determined as follows:

$$
\eta_{e x}=1-\frac{T_{a} S_{g e n}}{\left[1-\left(\frac{T_{a}}{T_{s}}\right)\right]} q_{a b x}
$$

As a result of the study, experimental data of the refrigerant R134a performance of the heat pump were investigated. As a result of the study, the operation of the compressor, the coefficient of performance, cooling capacity and condenser of the heat pump were obtained, the influence of the mass flow of air in the evaporator shell on the heat pump system was also studied. The numerical results of the obtained simulation are presented in graphical form.

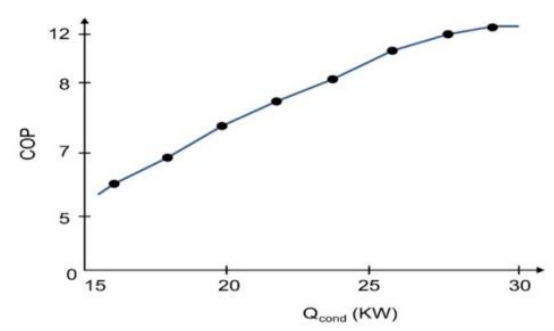

Fig.8 Dependence of the mass flow rate of water on the heat capacity of the condenser in the heat pump

From Figure 8 it can be seen that at the same water temperature at the inlet increases, the heat capacity of the condenser increases due to the mass flow of water.

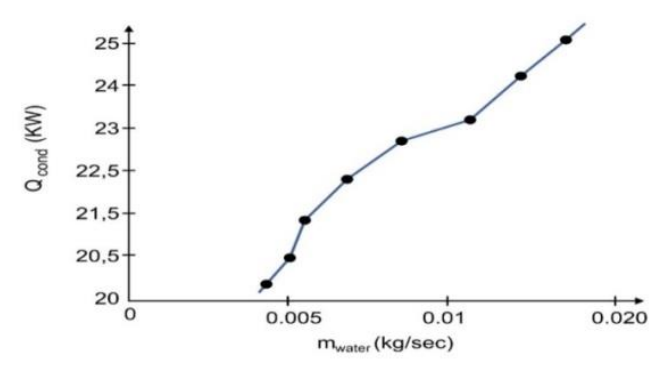

Fig.9 The dependence of the heat capacity of the heat pump condenser on the performance coefficient

Figure 9 shows the dependence of the heat capacity of the heat pump condenser on the coefficient of performance As the cooling capacity (Q.icp) was constant. When examining a heat pump, the heat capacity and efficiency of the condenser increases. 


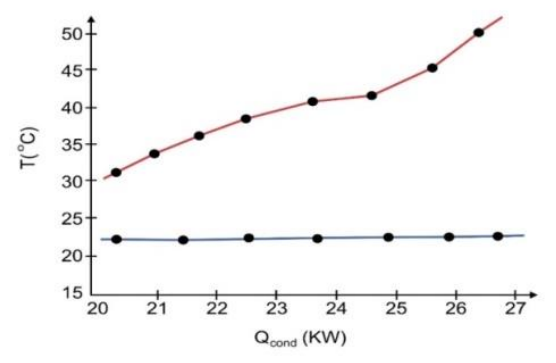

Fig.10 Dependence of the change in the heat capacity of the capacitor on the system temperature

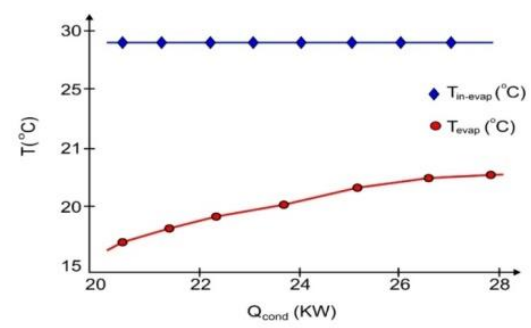

Fig.11 Dependence of the change in the heat capacity of the capacitor on the system temperature

Figures 10 and 11 show the efficiency of changing the heat capacity of the condenser according to the system temperature. The data studied do not depend on the temperature of the refrigerant in the heat exchanger. The temperature gradient of the outlet from the condenser increases with increasing heat capacity of the condenser, but there is a slight change in the temperature of the air at the outlet of the evaporator with a variation for the heat capacity of the condenser.

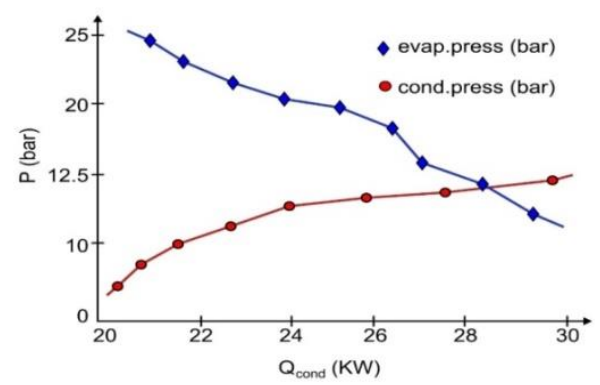

Fig.12 Dependence of the pressure in the condenser and the pressure in the evaporator on the heat capacity in the heat pump

Figure 12 shows the dependence of the pressure in the condenser and the pressure in the evaporator on the heat capacity in the thermal. As we can see on the graph, the pressure in the heat pump condenser decreases, while the evaporator pressure increases with increasing heat capacity of the heat pump condenser.

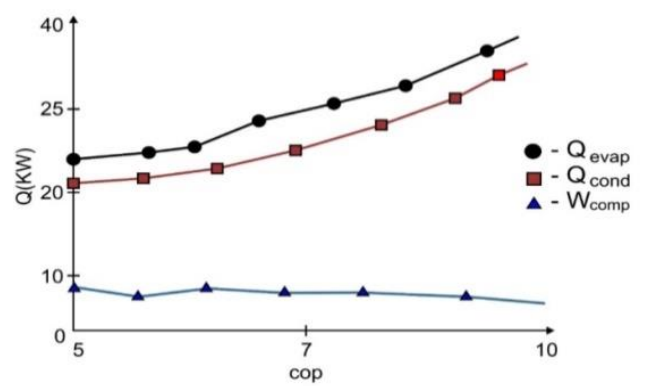

Fig.13 Dependence of the change in heat capacity on the mass flow rate of water

Figure 13 shows the dependence of the change in heat capacity on the mass flow rate of water. As can be seen from this dependence, the pressure drop between the condenser and the evaporator increases when the system is cooled, the compressor operation increases due to a decrease in the heat capacity of the condenser

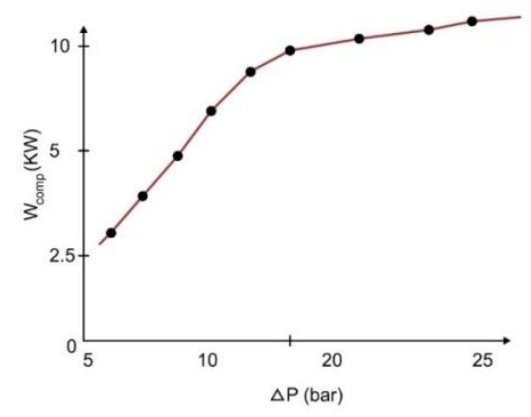

Fig.14 Dependence of heat pump energy on pressure change

Figure 14 shows a study of the dependence of heat pump energy on pressure changes. From this dependence, it can be observed that when the compressor is running, consumption decreases, therefore, efficiency increases. And when the heat capacity of the condenser increases, the efficiency increases, and the cooling capacity is almost the same. 


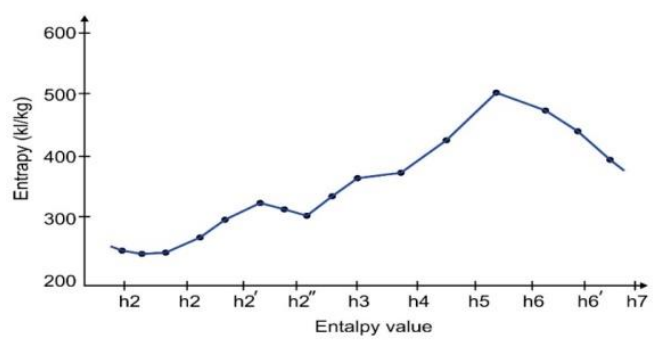

Fig.15 Dependence of entropy change on enthalpy in a heat pump

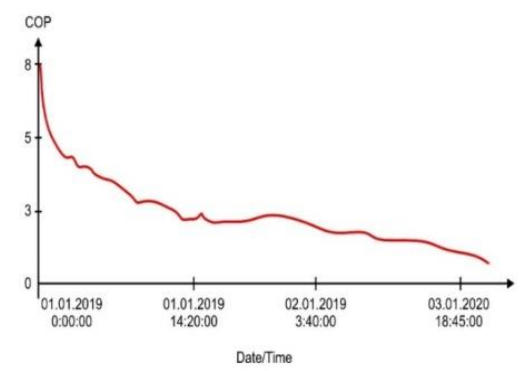

Fig.16 Graph of thermal pump COP change according to date and rime

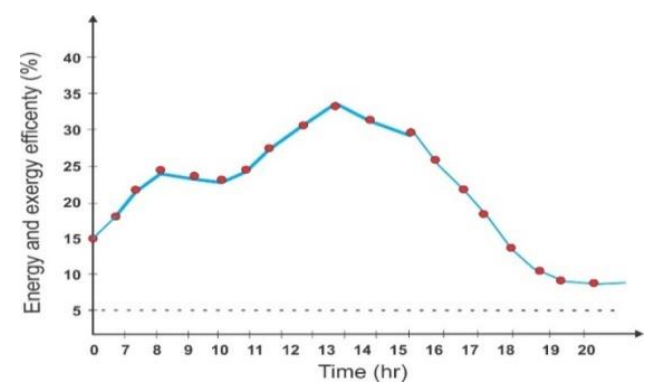

Fig.17 Dependence of energy and exergy performance

Despite the fact, that the two Figure 16 and 17 show approximately the same trend, energy efficiency is much higher, than exergy efficiency. The reason for this behavior is a significant deterioration in energy quality.

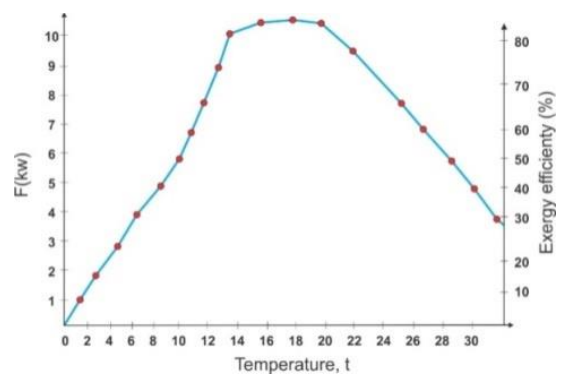

Fig.18 Dependence of energy on the temperature
Figure 18 shows, that in the summer period, energy efficiency increases with increasing ambient temperature at lunchtime, when the total solar activity is at its peak valueю

\section{Conclusion}

Experimental results for the seasonal efficiency of the heating air-water heating system in two temperature ranges, it is reasonable to assert that the heat pump system operates efficiently in heating mode at an accurately measured outdoor temperature typical of the climatic zone of Almaty (Kazakhstan). Economic analysis shows that the costs of consumed electrical energy from the heat pump system for the winter heating season in the considered temperature ranges are extremely effective. Experimental indicators of energy and exergy solar collectors with thermosiphon circulation with heat pumps work effectively in heating mode with accurately measured outdoor air temperature characteristic of the climatic zone of Almaty (Kazakhstan). Energy analysis shows that with the new flat solar collectors, the average annual values were $2.5 \mathrm{~kW}$, and also high, the COP system in November was $4 \%$.

\section{References}

[1] S. Kozarcanin, GB. Andresen, I. Staffell, "Estimating country-specific space heating threshold temperatures from national gas and electricity consumption data," Energy Build, vol.199, pp.368-80, 2019.

[2] M. Carragher, M. De Rosa, A. Kathirgamanathan, "Finn DP. Investment analysis of gas-turbine combined heat and power systems for commercial buildings under different climatic and market scenarios," Energy Convers Manage,vol.183, pp.35-49, 2019.

[3] X. Zheng, G. Wu, Y. Qiu, X. Zhan, N. Shah, N. Li et al,“ A MINLP multi objective optimization model for operational planning of a case study CCHP system in urban China, " Appl Energy, vol.210,pp.1126-40,2018.

[4] TX. Li, JX. Xu, DL. Wu, F. He, RZ. Wang," High energy-density and power-density thermal storage prototype with hydrated salt for hot water and space heating," Appl Energy,vol.248,pp.406-14,2019. 
[5] V. Tulus, D. Boer, LF. Cabeza, L. Jim'enez, G.Guill'en-Gosalbez, "Enhanced thermal energy supply via central solar heating plants with seasonal storage: a multi-objective optimization approach,"Appl Energy,vol.181,pp.549-61, 2016.

[6] DA. Chwieduk, "8 - Active solar space heating. In: Wang RZ, Ge TS, editors. Advances in Solar Heating and Cooling," Woodhead Publishing, pp. 151-202, 2016.

[7] G. Raam Dheep, A. Sreekumar, "Thermal reliability and corrosion characteristics of an organic phase change materials for solar space heating applications, " Journal of Energy, Storage”, vol.23,98-105, 2019.

[8] J.Hirvonen, H. ur Rehman, K. Siren', "Techno-economic optimization and analysis of a high latitude solar district heating system with seasonal storage, considering different community sizes," Sol Energy, vol.162,pp.47288,2018 .

[9] Hu. Rehman, J. Hirvonen, K. Siren',"Performance comparison between optimized design of a centralized and semidecentralized community size solar district heating system, " Appl Energy, vol. 229, pp. 1072-94, 2018.

[10] R. Renaldi, D. Friedrich,“ Technoeconomic analysis of a solar district heating system with seasonal thermal storage in the UK, "Appl Energy, vol.236,pp. 388-400, 2019.

[11] V. Tulus, MH. Abokersh, LF. Cabeza, M. Valles', L. Jimenez', D. Boer, "Economic and environmental potential for solar assisted central heating plants in the EU residential sector: contribution to the 2030 climate and energy EU agenda,"Appl Energy, vol.236,pp.318-319, 2019.

[12] J. Huang, J. Fan, S. Furbo, " Feasibility study on solar district heating in China,"Renew Sustain Energy Rev, vol.108, pp.53-64, 2019.

[13] J. Chu, CA. Cruickshank, " Solar-Assisted Heat Pump Systems: A Review of Existing Studies and Their Applicability to the Canadian Residential Sector, " Journal of Solar Energy Engineering, vol.136, no.041013,pp.1-.9, 2014.
[14] B. van der Heijde, A. Vandermeulen, R. Salenbien, L. Helsen,"Representative days selection for district energy system optimisation: a solar district heating system with seasonal storage," $\mathrm{Appl}$ Energy, viol.248,pp.79-94, 2019.

[15] G. Ciampi, A. Rosato, S. Sibilio," Thermoeconomic sensitivity analysis by dynamic simulations of a small Italian solar district heating system with a seasonal borehole thermal energy storage," Energy, vol.143,pp.757-771, 2018 .

[16] R.Omarov, S. Abdygaliyeva, D.Omar, M. Kunelbayev, "Integrated system for the use of solar energy in animal farm, "Scientia Iranica, vol. 24(6), pp. 3213-3222, 2017.

[17] R.Omarov, I.Stoyanov, S. Demesova M.Kunelbayev, Y. Yerzhigitov," Experimental studies of a heat pump with microprocessor control on an animal farm, " International Journal of Applied Engineering Research, vol.12(24), pp.14259-14267, 2017.

[18] Ivan Silva, Rogério Flauzino, Danilo Spatti, Renato Bossolan, Bruno Trevisam, Saulo Trento, "Asset Management of Power Transformers based on Data Analytics and Statistical Studies", WSEAS Transactions on Power Systems, pp. 202-208, Volume 14, 2019

[19] G. Kishor Babu, B. Madhu Kiran, "Improve the Voltage Level in HVDC Systems by using Modular Multilevel Converter", WSEAS Transactions on Power Systems, pp. 196-201, Volume 14, 2019

[20] Toshifumi Yuji, Che Xiaoxuan, Toshio Bouno, Noritsugu Kamata, "The Introduction of Base Power Supply used Surplus Electric Power from Photovoltaic System", WSEAS Transactions on Power Systems, pp. 190-195, Volume 14, 2019

[21] Danny Khoury, Fakheredine Keyrouz, "A Predictive Convolutional Neural Network Model for Source-Load Forecasting in Smart Grids", WSEAS Transactions on Power Systems, pp. 181-189, Volume 14, 2019 
[22] Sotirios Kokosis, Eleni Gati, Nikolaos Patsourakis, Stefanos Manias, "Comparative Evaluation of GaN Transistors and Si MOSFETs for Use in Inductive Power Transfer Systems of Biomedical Implantable Devices", WSEAS Transactions on Power Systems, pp. 172-180 Volume 14, 2019

\section{Creative Commons Attribution License 4.0} (Attribution 4.0 International, CC BY 4.0)

This article is published under the terms of the Creative Commons Attribution License 4.0

https://creativecommons.org/licenses/by/4.0/deed.en_US 